\title{
Negros y pardos propietarios de bienes raíces y de esclavos en el Buenos Aires de fines del período hispánico
}

\author{
Miguel A. Rosal
}

CONICET-Instituto Ravignani, Buenos Aires, Argentina

\begin{abstract}
El trabajo pretende ilustrar un aspecto poco conocido dentro de la problemática afroporteña; nos referimos a la capacidad para adquirir bienes inmuebles - terrenos y casasy esclavos que tenían los integrantes de la raza africana, en general de condición libre, pero también esclavizados, en el Buenos Aires tardocolonial, capacidad fundada sin duda en una significativa actividad laboral y, en especial, artesanal. En ese sentido, hacemos referencia a las características de los inmuebles, a los precios de los mismos, a su ubicación en el espacio urbano (distribución de los afroporteños según los barrios) y, por último, a la participación de negros y blancos en el mercado porteño de compraventa de bienes raíces y de esclavos.
\end{abstract}

\section{Introducción}

Poner nuestra atención en aspectos poco estudiados o directamente ignorados por otros investigadores de los procesos esclavistas hispanoamericanos es sólo un medio para acceder a la comprensión de la situación social de los afroporteños. Estos seres humanos - aunque pocas veces tratados como tal, y mucho menos en el caso de los esclavos, los cuales eran, desde un punto de vista jurídico, "una cosa con supervivencias crecientes del concepto de persona" según la definición de Petit Muñoz-1 eran especiales, no por lo bueno de su situación, sino por todo lo contrario. Al color de su piel se unía la pobreza, ésta derivada de aquél. Mala combinación, sin duda; combinación que sofocó las aspiraciones sociales del grueso de la negrada que desembarcó - compulsivamente, claro está- en las orillas del Plata. ${ }^{2}$ Sin embargo, hubo algunos integrantes de la raza africana que decidieron luchar - aunque calladamente - por la integración, la cual no fue totalmente lograda ya que después de todo el color de la piel es imborrable.

1 Petit Muñoz, Eugenio et alter: La condición jurídica, social, económica y política de los negros durante el coloniaje en la Banda Oriental, Montevideo, 1947, pág. 186.

2 La cuestión de la trata negrera la hemos abordado en nuestra ponencia "El tráfico esclavista y el estado sanitario de la ciudad de Buenos Aires (1750-1810)", en II Jornadas de Historia de la ciudad de Buenos Aires, Buenos Aires, 1988, págs. 231-240. 
A estos últimos está dedicada buena parte del presente estudio; ellos, para llegar a ser considerados como seres humanos, debían "parecerse" al blanco, actuar como él. Era importante aprender un oficio y, luego de años de esfuerzo, acceder quizás a la categoría de maestro. ${ }^{3}$ Años de trabajo, de privaciones, pero también de ahorro, significaban el logro de la ansiada libertad. Más tarde sería posible comprar un terreno y, por qué no, una casa - que no eran baratas-, lo que exigía que acudiera al despacho de un notario en el cual se celebraría un contrato de compraventa; ${ }^{4}$ veremos que estos contratos eran más asiduamente celebrados entre un afroporteño y un blanco que entre dos integrantes de la raza negra. Y si el blanco era dueño de esclavos, ¿qué impedía al negro ser amo de negros? Era necesario comprarlos, y así lo hicieron, aun cuando el precio de los mismos fuera más que considerable. ${ }^{5}$

Era preciso también pertenecer a cofradías religiosas frecuentadas por blancos, aunque hubiera, y las hubo, especiales para la "gente de color". ${ }^{6}$ Era menester, por fin, poner, al final de una trabajosa vida, las cosas en orden con Dios y con el Estado: había que otorgar un testamento, o más de uno, tal cual lo hacían los blancos. ${ }^{7}$

Conseguir estos logros era conseguir, por así decirlo, el certificado de ser humano; de segunda categoría, quizá, pero ser humano al fin. Sabemos que muchos no lo obtuvieron, pero los que sí lo hicieron, dejaron su testimonio. Al mismo, disperso en multitud de documentación, lo hemos buscado, hallado y analizado para tratar de comprender a estos seres humanos de color obscuro, que en alguna medida lograron parecerse a los de color claro.

3 Sobre este tema, ver nuestro artículo "Artesanos de color en Buenos Aires (1750-1810)", en Boletín del Instituto de Historia Argentina y Americana "Doctor Emilio Ravignani”, n. ${ }^{\circ} 27$, Buenos Aires, 1982, págs. 331-354.

4 Al respecto se puede consultar nuestra ponencia "Afroporteños propietarios de terrenos y casas (1750-1810)", en IV Jornadas de Historia de la ciudad de Buenos Aires, Buenos Aires, 1988, págs. 363-380.

5 Un intento de aproximación al problema lo constituye nuestro trabajo "Precios internos de esclavos en la ciudad de Buenos Aires (1750-1820)", en VI Jornadas de Historia Económica, Córdoba, 1984, págs. 603-617.

6 Esta problemática la hemos tratado en nuestro artículo "Algunas consideraciones sobre las creencias religiosas de los africanos porteños (1750-1820)", Investigaciones y Ensayos, n. ${ }^{\circ} 31$, Buenos Aires, 1984, págs. 369-382.

7 Sobre el tema se puede consultar a Tau Anzoátegui, Víctor: Esquema histórico del derecho sucesorio del medievo castellano al siglo XIX, Buenos Aires, 1971. La cuestión ha sido considerada en nuestro estudio "Diversos aspectos relacionados con la esclavitud en el Río de la Plata a través del estudio de testamentos de afroporteños, 1750-1810”, en Revista de Indias, v. LVI, n. . 206, Madrid, eneroabril 1996, págs. 219-235. 


\section{Afroporteños propietarios de bienes raíces}

La figura del negro propietario ha sido poco y nada examinada por la historiografía afro-rioplatense, lo cual llama la atención, pues es bastante significativa la cantidad de documentación que ilustra sobre el fenómeno. ${ }^{8}$ Nos referimos a los afroporteños de condición libre, en general, pero en algunos casos esclava, que mediante donación o compra (a crédito o al contado, con dinero prestado o ahorrado, fruto de su esfuerzo personal) lograba obtener terrenos, o casas, en el ejido o, principalmente, en la traza de la ciudad, participando activamente en el mercado inmobiliario urbano. ${ }^{9}$

Es necesario realizar, antes de ocuparnos de nuestro tema específico, una sucinta consideración acerca del entorno geográfico. El estudio de antiguos planos porteños, en especial los confeccionados hacia el fin del período hispánico, como por ejemplo la división eclesiástica de 1769 y la división en cuarteles de 1778, nos mostró distintas divisiones territoriales de la ciudad de Buenos Aires. ${ }^{10}$ Sin embargo, nuestra propia tarea de investigación y análisis nos llevó a intentar una nueva, que, creemos, por ser más simple ayuda a comprender la problemática.

Se repartió la urbe en seis bloques: el Bajo del Río (hacia el este) y cinco sectores que agrupan dentro de sí a pequeños barrios, el Sur (Concepción, Alto de San Pedro, Hospital, Barracas, Matadero de Santo Domingo), el Sudoeste (Montserrat y San Juan), el Central (Catedral, San Francisco, Santo Domingo, San Ignacio y La Merced), el Norte (Santa Catalina, Retiro, Socorro, Recio, Recoleta) y el Noroeste (San Nicolás, San Miguel, Santa Lucía y La Piedad).

Hemos encontrado casi un centenar de documentos que se refieren a la compraventa de casas donde al menos uno de los participantes era afroporteño. El cuadro 1 nos permite observar el número de operaciones reali-

8 Una interesante excepción la constituye el trabajo de Mallo, Silvia C.: "Población afroargentina: del peculio al patrimonio y la propiedad”, XII Congreso Nacional de Arqueología Argentina, t. II, La Plata, 1999, págs. 434-439. En otro trabajo se señala "la tendencia en especial de las mujeres, todavía esclavas o libres, a asegurarse la propiedad de sitios, sus propios ranchos o casitas". Cfr. Goldberg, Marta B. y Mallo: "La población africana en Buenos Aires y su campaña. Formas de vida y de subsistencia (1750-1850)", Temas de África y Asia, n. ${ }^{2}$, Buenos Aires, 1993, pág. 59.

9 Un panorama sobre el mercado inmobiliario urbano porteño durante el siglo XVIII y primeros años del XIX se puede encontrar en Saguier, Eduardo R.: "El mercado inmobiliario urbano y la movilidad social en la ciudad rioplatense (siglo XVIII)", Estudios Sociales, año 5, n. ${ }^{\circ} 8$, Santa Fe, primer semestre de 1995, págs. 77-100.

10 Los planos se pueden consultar en Taullard, A.: Los planos más antiguos de Buenos Aires (1580-1880), Buenos Aires, 1940. 
zadas en las seis últimas décadas del período colonial, repartidas según los distintos sectores de la ciudad. Vemos que en los orientados hacia el sudsudoeste y nor-noroeste de la urbe es donde se lleva a cabo la mayor cantidad de las mismas, mientras que en el Bajo y en el sector Central son bastante exiguos los casos registrados.

\section{CUADRO 1}

AFROPORTEÑOS PROPIETARIOS DE INMUEBLES. COMPRAVENTA DE CASAS (1750-1810)

\begin{tabular}{lccccccc} 
& Sur & Sudoeste & Central & Norte & Noroeste & Bajo & Total \\
\hline $1750-59$ & 2 & 2 & - & 1 & 3 & 2 & 10 \\
$1760-69$ & 3 & 1 & 1 & 3 & - & - & 8 \\
$1770-79$ & 4 & 3 & - & 5 & 4 & 2 & 18 \\
$1780-89$ & 2 & 6 & - & 8 & 2 & 1 & 19 \\
$1790-99$ & 4 & - & 2 & 6 & 2 & - & 14 \\
$1800-10$ & 4 & 10 & 1 & 6 & 2 & - & 23 \\
\hline Total & 19 & 22 & 4 & 29 & 13 & 5 & 92
\end{tabular}

Si bien la mayoría de los negros y pardos participantes en la compraventa es de condición libre, algunos de ellos eran esclavos. En ese sentido, es conveniente aclarar que entre los intereses humanos del esclavo ${ }^{11}$ se encontraba el peculio, esto es, el derecho a adquirir mediante trabajo personal el que podemos llamar — según Petit Muñoz- "peculio liberatorio", es decir dinero destinado a su manumisión..$^{12}$ Aun así, Levaggi señala que

“...la jurisprudencia...no fue uniforme. No tuvieron pleno respaldo las prerrogativas de los dueños de esclavos, ni fue siempre reconocido el derecho de éstos al rescate contra la voluntad de aquéllos, por aplicación de los principios del derecho dominial. Analizados todos los antecedentes, puede sin embargo destacarse una tendencia - de la que participa nada menos que la real persona - favorable a la liberación por el justo precio, y cuyo desarrollo futuro conducirá a la abolición de la esclavitud". ${ }^{13}$

11 Entre los intereses humanos del esclavo señalados por Petit Muñoz, podemos nombrar: la vida, el sustento, la integridad corporal (con limitaciones), la salud, la libertad de matrimonio, la convivencia efectiva de los cónyuges en el matrimonio, el nombre y el estado civil, la asistencia judicial, el peculio, la moralidad, el derecho de asociación, el reposo y aun el esparcimiento (aunque con grandes limitaciones), etc.. Cfr. Petit Muñoz et alter: La condición jurídica ... , pág. 289.

12 Ibídem, págs. 214-215.

13 Levaggi, Abelardo: "La condición jurídica del esclavo en la época hispánica", en Revista de Historia del Derecho, n. ${ }^{\circ}$ 1, Buenos Aires, 1973, pág. 140. 
Además del liberatorio, existía para el esclavo la posibilidad de adquirir otro tipo de peculio — vía donación por parte del amo - " "al cual la ley no impone destino determinado, y cuya conservación no condiciona a fin especial alguno". ${ }^{14}$ Entre otras facultades, el esclavo podía disponer libremente de él e, incluso, comerciarlo, previa venia del amo. ${ }^{15}$

Sin embargo, en la realidad no siempre ocurría así. El testamento de María Rita Durán, negra libre, de nación Angola, casada con Pedro, negro esclavo de Don Antonio Warnes, es ilustrativo al respecto:

“...los cortos bienes que tenemos los hemos adquirido con nuestro trabajo personal, y mi esposo con consentimiento de su amo, y no obstante eso y de ser esclavo quien por lo mismo no tiene derecho a ningún bienes, no obstante por obviar toda y cualesquiera disputa que pudiera ocasionarse y que yo como libre pueda disponer de los bienes sin embarazo el más leve de su amo...hacía renuncia a mi favor de cuantos derechos o acciones pudiesen competirle por su esclavo...". ${ }^{16}$

De allí que llame la atención el hecho de que la mujer necesite la venia marital para vender un bien, cuando su esposo es esclavo:

“...Sépase que por esta pública escritura que yo, María Magdalena Barragán, vecina de esta ciudad, mujer legítima de Pedro Nolasco García, negro esclavo, de quien obtengo la venia necesaria para la extensión de este instrumento, que me la dio, y concedió, en bastante forma en presencia del escribano actuario de que da fe otorgo que vendo....". ${ }^{17}$

14 Petit Muñoz et alter: La condición jurídica ... , pág. 219. El capítulo 18 del Código Negro Carolino - que si bien no entró en vigencia tiene disposiciones que nos dan la pauta de los criterios que imperaban hacia el fin del período colonial - trata sobre el peculio de los esclavos. Cfr. en Malagón Barceló, Javier: Código Negro Carolino (1784), Santo Domingo, 1974, págs. 199-201. La Real Cédula del 31 de mayo de 1789 (Code Noir) se refiere — tácitamente- al derecho al peculio en el capítulo I (Educación) al establecer que “...se les explique a los esclavos la doctrina cristiana todos los días de Fiesta de precepto, en que no se les obligará, ni permitirá trabajar para sí, ni para sus dueños...”. A su vez, el capítulo III (Ocupación de los esclavos) decreta que “...debiendo principiar y concluir el trabajo de sol a sol, les queden en este mismo tiempo dos horas en el día para que las empleen en manufacturas u ocupaciones que cedan en su personal beneficio y utilidad...". Cfr. en "Cedulario referente al régimen colonial de la esclavitud de los negros", en Revista de la Biblioteca Nacional, t. 16, n. ${ }^{\circ} 42$, Buenos Aires, segundo trimestre de 1947, págs. 351-363; (los subrayados son nuestros).

15 Una perspectiva diferente sobre la situación se puede observar en el trabajo de Saguier: "La naturaleza estipendiaria de la esclavitud urbana colonial. El caso de Buenos Aires en el siglo XVIII", Revista Paraguaya de Sociología, año 26, n. ${ }^{\circ} 74$, enero-abril de 1985, págs. 45-54. Sobre la "esclavitud a jornal" en otra sociedad esclavista, se puede consultar el notable trabajo de Aguirre, Carlos: Agentes de su propia libertad. Los esclavos de Lima y la desintegración de la esclavitud, 1821-1854, 2da. edición, Lima, 1995, cap. 4.

16 Archivo General de la Nación (en adelante AGN), Protocolos Notariales (en adelante PN), registro (en adelante r.) 5, 1794, f. 315v., 29 de octubre de 1794 (el subrayado es nuestro).

17 AGN, PN, r. 1, 1785, f. 158v., 23 de abril de 1785 (el subrayado es nuestro). 
Relacionadas con estas normas de derecho civil y comercial, están las del derecho sucesorio referidas a la herencia de los hijos esclavos. Al respecto pueden darse dos situaciones: la primera de ellas es que los padres no incluyan como heredero a su hijo esclavo, precisamente por su condición servil $;{ }^{18}$ la segunda es que sí lo hagan, pero a su vez aquí podemos encontrar tres casos. Primero, que el recibir la herencia por parte del hijo esclavo dependa de una ulterior venia del amo, ${ }^{19}$ caso en que hay que tener en cuenta que una herencia quizá permitiría al esclavo comprar su libertad y no siempre los amos, como hemos visto, se mostraban dispuestos a otorgarla; segundo, que la venia del amo ya esté concedida al momento de redactar el testamento; ${ }^{20}$ tercero, que se lo incluya directamente como heredero. ${ }^{21}$

Este último caso podría considerárselo sólo formal, pues en última instancia sería el amo quien tuviera la palabra definitiva. De cualquier modo, teniendo en cuenta, como ya dijimos, que el esclavo podría llegar a rescatar su libertad mediante un aporte hereditario, sabemos que existió una

"dualidad de criterios interpretativos acerca del derecho de los esclavos a comprar su libertad, esto es, si ese derecho lo tenían a pesar de la voluntad opuesta del señor, o si era indispensable su conformidad". ${ }^{22}$

Hacia el final de la época colonial se habría impuesto el primer criterio.

En todo caso, la documentación consultada revela que hubo esclavos que con venia de su amo poseían bienes y participaron de la compraventa, prefiriendo, incluso, comprar un inmueble antes que su libertad. La posible explicación de este fenómeno es que la condición de su esclavitud no era una carga demasiado pesada de sobrellevar. El trato dado a los esclavos rioplatenses fue, en general, benigno, y los trabajos desempeñados por éstos,

18 “...y no incluyo por heredero a mi hijo Silvestre por ser esclavo". Ver testamento de Francisco Aguilar, negro, en AGN, PN, r. 6, 1777, f. 118v., 18 de junio de 1777.

19 “...nombro por mis únicos y universales herederos a los enunciados, mis hijos y de dicho mi marido, para que los hayan, hereden y gocen por iguales partes, bien entendido que para que puedan percibir las partes que les correspondan a los que como llevo dicho son esclavos de San Francisco hayan de pedir venia a sus amos, la que han de hacer constar, y en caso de que no se la concedan se haya de repartir entre los libres, la parte que a los dichos esclavos les tocase...". Ver testamento de María Catalina Cáceres, parda, en AGN, PN, r. 6, 1762-1763, f. 57, 22 de septiembre de 1762.

20 En su testamento, María Rodríguez, negra, deja como herederos a sus hijos, uno de los cuales, Mariano, es esclavo del oidor de la Audiencia, Don. Sebastián de Velazco, “...quien por un efecto de su piadoso corazón y generoso ánimo le ha habilitado para que pueda heredarme en la parte que le corresponda....'. Ver testamento en AGN, PN, r. 2, 1789, f. 81, 17 de febrero de 1789.

21 Sería el caso de Teresa Velázquez, afroporteña, que tiene dos hijas, una libre y la otra esclava, y ambas son herederas. Ver testamento en AGN, PN, r. 5, 1766, f. 188, 15 de julio de 1766.

22 Levaggi: "La condición jurídica ... ", pág. 139. 
de carácter doméstico y artesanal principalmente, no hacían la vida excesivamente dura para el esclavo porteño, al menos si la comparamos con la que debían sufrir los inmersos en otro tipo de sociedades esclavistas, aun de las que formaban parte del imperio colonial hispánico.

En otros casos, afroporteños de condición libre poseían bienes raíces, si bien integrantes de su familia permanecían en esclavitud. Sin duda estos últimos contaban con la casa, el alimento y la protección legal que les daba el amo, especialmente si esa función la ejercía una comunidad religiosa (ventajas que muchos blancos pobres no tenían, al menos en lo que se refiere a casa y comida). En su testamento, María Catalina Cáceres, parda libre, esposa de Santiago, negro esclavo del Convento de San Francisco, declara tener siete hijos, cuatro libres y tres esclavos del Convento; posee una casita de un tirante, un cuarto de media agua de adobe cocido y techo de tejas, y cocina, construcciones que se alzan en un sitio de $171 / 2 \times 70$ varas, ubicado en los extramuros de la ciudad, "calle derecha de San Juan oeste". Probablemente una comunidad religiosa era, en general, un amo más blando que un particular, y de allí que Santiago, posiblemente, no se sintiera tan desventurado con su situación. Desde ese punto de vista se entiende por qué la esposa, a pesar de poseer bienes, no compraba la libertad de su esposo e hijos. ${ }^{23}$ En otros casos podía ocurrir lo que le sucedió a María Mercedes Rodríguez, parda libre, quien, en su testamento, declara estar casada con Juan José González, negro esclavo del Convento de Santo Domingo. Posee un sitio de $171 / 2 \times 22$ varas y en él construida una casa de media agua, de ladrillo cocido $\mathrm{y}$ techo de tejas, con un cerco de pared y algunos frutales. Dichos bienes los obtuvo con su industria y trabajo, "criando y lavando", y en ellos no tiene participación el marido pues "en nada me ha ayudado, antes por el contrario varias ocasiones lo he vestido y pagado el jornal a sus amos". Es comprensible que esta mujer no deseara sacrificarse, vendiendo su casa, para liberar a un marido que no era demasiado afecto al trabajo. ${ }^{24}$

En otros casos el esclavo solicitaba y recibía el permiso para vivir con su esposa e hijos alejado del núcleo familiar del amo, por lo cual parece entendible la compra de un terreno para construir una vivienda o directamente tratar de acceder a una casa. Don Antonio Miguel Moreno, mayor ecónomo de la Parroquia de San Nicolás, vende al negro Manuel, esclavo de la Iglesia y que recibe la venia de los religiosos, un sitio para que pueda hacer un rancho para que viva con su mujer y sus hijos; el terreno per-

23 AGN, PN, r. 6, 1762-1763, f. 57, 22 de septiembre de 1762.

24 AGN, PN, r. 2, 1790, f. 196, 24 de mayo de 1790. 
tenece a la Parroquia y es de $171 / 2 \times 70$ varas, con un precio de 300 pesos y es pagado por partes iguales entre el negro y Don Bartolo Noriega. Unos meses más tarde el esclavo hace cesión y traspaso del bien inmueble a su mujer y sus hijos. ${ }^{25}$ Estos casos serían más frecuentes cuando el resto de la familia fuera de condición libre, para evitar posibles excesos de los amos, esto es, aprovechando la condición de esclavo de uno de los integrantes del grupo familiar, pretendieran tratar a los libres como personas no manumitidas. Los que se beneficiaban con estos permisos pasaban a engrosar aquella categoría de esclavos donde, prácticamente, el único signo de dependencia era la entrega del jornal al amo: los "semilibres"; ${ }^{26}$ es muy probable que Anastasio Arroyo, natural del Brasil, casado, esclavo de Don Tomás Arroyo, oficial de zapatero desde hace seis años, que vive en el Alto en casa propia, y Fermín Gómez, negro esclavo de Don Vicente Montoya, natural de Buenos Aires, casado, oficial de zapatero desde hace doce años, que vive junto a Santo Domingo en casa propia, fueran integrantes de estos últimos. ${ }^{27}$ Una vez dentro de este engranaje, es factible que antes de liberarse el mismo prefiera comprar la carta de libertad de la esposa, la cual en el futuro engendrará hijos libres y/o libertar a sus hijos esclavos. ${ }^{28}$

De cualquier modo, se dieron casos en que el dinero obtenido por la venta de un bien inmueble fue destinado al logro de la manumisión de los miembros de la familia aún esclavos. Asencio Urquizu, pardo libre, y su mujer, Inés Gutiérrez, parda esclava de Doña Ana María Gutiérrez, con expreso consentimiento de ésta, venden a Don Marcos Gutiérrez - cuyo eventual parentesco con Doña Ana María no se hace constar- una casa ubicada en el barrio de San Juan, cuyo sitio es de 35 x 70 varas, con un precio (significativo) de 1.240 pesos. Sabemos que un mes más tarde Urquizu liberta a su hija María Rosa, de cuatro años, en 150 pesos; para ese tiempo, su esposa, al parecer, ya era libre. ${ }^{29}$ Todo indica que parte del dinero de

25 AGN, PN, r. 4, 1800-1801, fs. 150v. y 152, 14 de enero de 1801, y f. 265v., 11 de diciembre de 1801 .

26 Para Eduardo Saguier "la esclavitud estipendiaria venía a equivaler a una libertad condicionada". Cfr. Saguier: "La naturaleza estipendiaria ...", pág. 46.

27 AGN, Interior, legajo 9, expediente 5, IX-30-2-3, "Lista de zapateros, guarnicioneros, lomilleros y curtidores que se presentaron a consecuencia del bando" (se refiere al dictado por el virrey Vértiz con relación al censo de artesanos), fs. 11-11v., 4 de agosto- $1 .^{\circ}$ de septiembre de 1780; ver también el citado testamento de María Mercedes Rodríguez en AGN, PN, r. 2, 1790, f. 196, 24 de mayo de 1790.

28 Este tipo de estrategias familiares se encuentra muy bien documentado para el caso de Lima durante el siglo XIX por Carlos Aguirre. Cfr. Aguirre: Agentes de su propia libertad ... , cap. 6.

29 AGN, PN, r. 6, 1754-1756, f. 133v., 16 de mayo de 1755 y f. 188 v., 14 de junio de 1755, respectivamente. 
la venta sirvió para que el pardo libertara a su familia; el sobrante sin duda alcanzaba para adquirir otra casa, por cierto más modesta, pero sin que la familia resignara su status de propietario. Si bien no sabemos si esto ocurrió realmente, lo que sí sabemos es que, años después, en su testamento Urquizu declara ser propietario de varios terrenos, además de su casa. ${ }^{30}$

En cuanto a los inmuebles en sí (casas), en contados casos se especifica el estado de los mismos, e incluso en otros ni siquiera se los describe; además, no siempre las dimensiones de los terrenos son iguales, lo cual no facilita las comparaciones. De allí que se hace difícil poder cotejar datos, pues éstos son disímiles, tanto de década en década como para los barrios en el transcurso de un mismo decenio. Aun así, intentamos acercarnos al problema y calculamos, grosso modo, un precio general de una casa "media" para todo el período: una vivienda de adobe cocido y techo de tejas, que constara de una sala, aposento y cocina, con un pozo de balde, cerco de tuna y algún frutal, y cuyo sitio fuera de $171 / 2 \times 70$ varas, costaba aproximadamente de 400 a 450 pesos, notándose un alza un tanto aguda para la última década del período considerado.

De cualquier modo, hemos encontrado operaciones donde el precio es más alto. Bartolo del Cano, pardo libre, de oficio zapatero, compra en 1773 una casa sita en el barrio de las Catalinas, cuya sala es de dos tirantes, de ladrillo cocido y techo de teja, y una cocina de media agua, de adobe crudo, todo esto edificado en un sitio de $171 / 2 \times 52^{1 / 2} 2$ varas, donde se encuentran plantados varios árboles frutales; el precio es de 500 pesos. ${ }^{31}$ Para 1779 el pardo ha agregado otras construcciones (un aposento, otra sala de media agua, dos hornos, un pozo de balde) que indudablemente revalorizan su propiedad, ya que la vendió en 1.400 pesos. ${ }^{32}$ Juan Sarto, pardo libre, compra en 1801 una casa, sita en el barrio de San Juan, que consta de zaguán con altillo, dos salas, corredor, patio, un cuarto, cuarto de criados, un lugar común y pozo de balde; el terreno es de $103 / 4 \times 481 / 2$ varas, cercado con pared; su precio, realmente importante por tratarse de una operación realizada por un afroporteño, es de 2.800 pesos. ${ }^{33}$

En cuanto a los precios de terrenos, sólo se han considerado los que tenían las dimensiones standard (171/2 $\times 70$ varas), es decir, lo que generalmente se llamaba un "cuarto de tierra" — si bien hemos encontrado sitios

30 AGN, Sucesiones, n. ${ }^{\circ}$ 8598, año 1790, 4 de abril de 1789.

31 AGN, PN, r. 5, 1773, f. 44, 25 de febrero de 1773.

32 AGN, PN, r. 5, 1779, f. 325, 30 de octubre de 1779.

33 AGN, PN, r. 1, 1800-1801, f. 381v., 14 de diciembre de 1801. 
más pequeños que recibían la misma denominación-, y los de 70 varas de fondo, obteniéndose el precio promedio sobre la base de las varas de frente; los datos se han agrupado en el cuadro 2. Al haberse considerado sólo las compraventas donde al menos uno de los participantes era afroporteño, no son demasiados los datos hallados (81 casos); sin embargo sirven, creemos, para tener una idea sobre la cuestión.

\section{Cuadro 2}

AFROPORTEÑOS PROPIETARIOS DE INMUEBLES. PRECIOS DE TERRENOS (1750-1810)

\begin{tabular}{|c|c|c|c|c|c|c|c|c|c|c|}
\hline & \multicolumn{2}{|c|}{ Sur } & \multicolumn{2}{|c|}{ Sudoeste } & \multirow[t]{2}{*}{ Central } & \multicolumn{2}{|c|}{ Norte } & \multicolumn{2}{|c|}{ Noroeste } & \multirow[t]{2}{*}{ Bajo } \\
\hline & Traza & Ejido & Traza & Ejido & & Traza & Ejido & Traza & Ejido & \\
\hline \multirow[b]{2}{*}{$1750-1759$} & 3 & - & 2 & - & - & & - & - & - & - \\
\hline & 2,39 & - & 3,71 & - & - & 7,99 & - & - & - & \\
\hline \multirow[b]{2}{*}{$1760-1769$} & 2 & - & - & - & & - & - & 4 & - & - \\
\hline & 3,85 & - & - & - & 8,87 & - & - & 5,85 & - & \\
\hline \multirow[b]{2}{*}{$1770-1779$} & - & - & 1 & 1 & - & & - & - & - & - \\
\hline & - & - & 11,42 & 8,57 & - & 1,56 & - & - & - & \\
\hline \multirow[b]{2}{*}{$1780-1789$} & 4 & 2 & 4 & 5 & 2 & 6 & - & 1 & 1 & - \\
\hline & 12,28 & 7,14 & 9,16 & 4,15 & 12,57 & 10,82 & - & 8,00 & 6,28 & \\
\hline \multirow[b]{2}{*}{ 1790-1799 } & 3 & 3 & 6 & & - & & 1 & 3 & - & - \\
\hline & 16,46 & 4,83 & 8,94 & 7,71 & - & 2,85 & 5,14 & 17,18 & - & \\
\hline & 7 & 1 & 3 & 5 & - & - & - & 2 & 1 & - \\
\hline $1800-1810$ & 15,09 & 11,42 & 15,80 & 6,96 & - & - & - & 14,28 & 8,57 & \\
\hline
\end{tabular}

Observaciones: en la fila superior, correspondiente a cada década, se indica la cantidad de operaciones registradas; en la inferior, el precio promedio de la vara de frente.

Salvo en un caso (barrio Norte, quinta década), los precios en la traza de la ciudad son más altos que los registrados en el ejido, y aun así encontramos 59 terrenos ubicados en aquélla. Esto obedecería a una conjunción de causas: mayor seguridad personal (o sea, estar menos expuesto al bandolerismo de la época); mayor comodidad (estar cerca de los servicios más elementales); deseo de integración social y, además, poseer un respaldo económico lo suficientemente considerable que permitiera una inversión, o al menos iniciarla, en bienes inmuebles situados en la traza de la ciudad. De todos modos, es probable que al ser el universo considerado tan peque- 
ño, ${ }^{34}$ el cuadro 2 no alcance a reflejar la situación real; en todo caso, podemos advertir los altibajos, agudos por momentos, que sufrieron los precios de los terrenos a lo largo del período.

Respecto a la distribución geográfica, los terrenos ubicados hacia el sud-sudoeste de la ciudad son definitivamente mayoritarios, más del doble de los situados en el nor-noroeste.

Cabe destacar que no hemos hallado datos sobre sitios de 70 varas de fondo ubicados en el Bajo; tal situación no debe extrañar, pues en muchos casos las varas de fondo terminaban en "la inmediación del... paseo transitorio del Bajo del Río", ${ }^{35}$ en las barrancas, ${ }^{36}$ o directamente lindaban con el río, siendo probable también que por esta razón sus precios fueran más bajos que en otros sectores de la urbe. ${ }^{37}$

Sin embargo, para tener una idea más acabada de la distribución por barrios en función de una eventual preferencia afroporteña por algún sector de la ciudad determinado, hemos confeccionado el cuadro 3, realizado a través de la consulta de una variedad de documentación, como por ejemplo testamentos, donaciones, tasaciones, etc., además de las compraventas de terrenos y casas; sólo en la columna "s/i barrio" (sin indicar barrio) se han utilizado exclusivamente operaciones de compraventa.

Ahora sí, el sector Sudoeste (en especial, Montserrat) se va perfilando como el que durante las primeras décadas de vida independiente daría en llamarse "el barrio del tambor", evidentemente preferido por los afroporteños ${ }^{38}$ si bien son considerables los asentamientos en el norte y en el sur de la ciudad, y no menos importante es el número de casos en donde no está especificado el barrio (aunque en disminución hacia el último tra-

34 En cualquier caso, el número de casos hallados, tanto en el rubro compraventas de casas como en el de las de terrenos y en donde al menos uno de los participantes es afroporteño, constituye la totalidad, con algún margen de error despreciable, de los registrados en los Protocolos Notariales porteños desde 1750 a 1810 .

35 En 1821, María Eduarda y Bernardina Videla, pardas libres, declaran que 14 años atrás —en 1807- habían vendido a su hermana Joaquina una casita sita en el Bajo, cuyo terreno era de $71 \frac{1}{2}$ varas de frente al oeste "y las que se hallen... hasta la inmediación del camino del Bajo del Río..." de fondo al este. AGN, PN, r. 2, 1821, f. 7, 3 de enero de 1821.

36 María Juliana Abila, parda libre, compra un sitio de 16 varas de frente y "de fondo desde el frente a las barrancas del río" en 62 pesos. AGN, PN, r. 3, 1775-1776, f. 491v., 20 de agosto de 1776.

37 Petrona Zavala, negra libre, compra un sitio que por el este linda con el río en 50 pesos. AGN, PN, r. 5, 1753, f. 177v., 30 de abril de 1753. Isabel Suárez, negra libre, compra un terreno lindero con el río, en 65 pesos, en 1771; años después, en 1783, lo vende en 88 pesos. AGN, PN, r. 3, 1771, f. 223,14 de octubre de 1771 y r. 1, 1783, f. 322v., 18 de octubre de 1783 .

38 De este tema nos hemos ocupado en "Negros y pardos en Buenos Aires, 1811-1860", Anuario de Estudios Americanos, t. LI, n. ${ }^{\circ}$ 1, Sevilla, 1994, págs. 165-184. 
mo del lapso en estudio, lo cual puede significar simplemente una mayor tendencia a la precisión por parte de los notarios que desempeñaron sus funciones hacia el fin de la época colonial). En la mayoría de los casos analizados los afroporteños involucrados, directa o indirectamente, en las distintas operaciones inmobiliarias son personas de condición libre, las cuales por razones sociales y económicas tendían a ubicarse hacia la periferia de la ciudad; en efecto, los inmuebles sitos en el centro porteño eran más caros y estaban habitados por el patriciado de la ciudad, y sólo los afroporteños de condición esclava que vivían junto a sus amos ocupaban ese sector de la urbe..$^{39}$

\section{CUADRO 3}

AFROPORTEÑOS PROPIETARIOS DE INMUEBLES.

DISTRIBUCIÓN POR BARRIOS (1750-1810)

\begin{tabular}{lrrrrrrrr} 
& Sur & Sudoeste & Central & Norte & Noroeste & Bajo & s/i barrio & Total \\
\hline $1750-59$ & 11 & 5 & 3 & 9 & 5 & 8 & 13 & 41 \\
$1760-69$ & 12 & 10 & 6 & 8 & 5 & 1 & 14 & 42 \\
$1770-79$ & 9 & 10 & 1 & 9 & 9 & 5 & 26 & 43 \\
$1780-89$ & 16 & 36 & 10 & 25 & 12 & 5 & 16 & 104 \\
$1790-99$ & 21 & 30 & 5 & 22 & 11 & - & 7 & 89 \\
$1800-10$ & 19 & 53 & 1 & 17 & 9 & - & 7 & 99 \\
\hline Total & 88 & 144 & 26 & 90 & 51 & 19 & 83 & 418
\end{tabular}

Tratamos de enfocar la participación de los afroporteños en el mercado local de compraventa de inmuebles desde distintos ángulos: el sexo y la condición legal (libre o esclavo) de los involucrados, y también analizamos si las operaciones inmobiliarias se realizaban más frecuentemente entre integrantes de la raza africana, o entre uno de ellos y un blanco, y en este último caso, si la persona de raza blanca integraba el conjunto de la plebe u ocupaba un lugar más destacado dentro del espectro social rioplatense (la diferencia nos la dan los documentos de la época, al referirse a este último grupo de personas con el tratamiento de "Don").

39 Sobre este tema se puede consultar el trabajo de Johnson, Lyman L. y Socolow, Susan M.: "Población y espacio en el Buenos Aires del siglo XVIII", Desarrollo Económico, v. 20, n. o 79, Buenos Aires, octubre-diciembre de 1980, págs. 329-349. 


\section{CuAdro 4}

COMPRAVENTA DE BIENES RAÍCES ENTRE AFROPORTEÑOS Y BLANCOS (1750-1810)

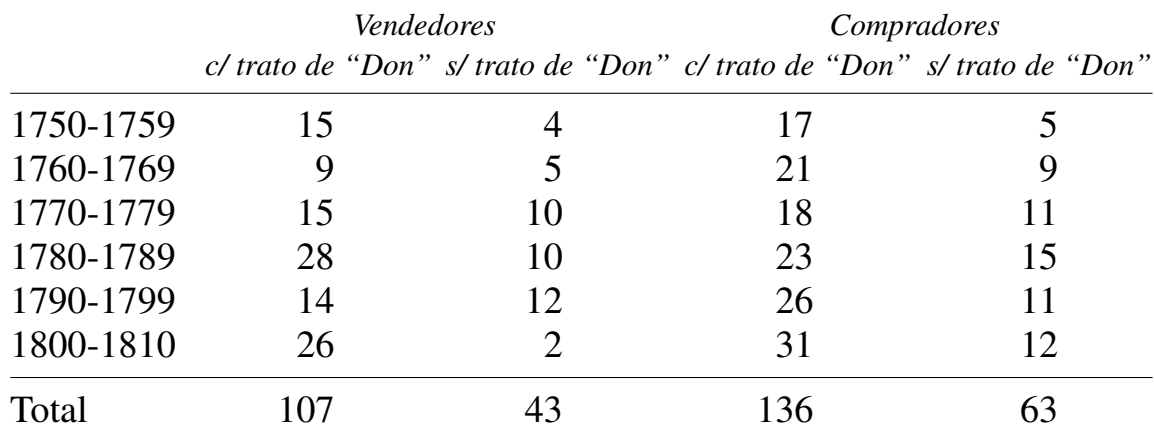

Observaciones: 7 vendedores y 5 compradores son de condición esclava; uno de cada categoría realiza la operación inmobiliaria respectiva con blancos que no reciben tratamiento de "Don".

Desde el punto de vista del sexo, a través de la investigación hemos notado que los hombres parecen más activos, tanto en la compra como en la venta de inmuebles. Eso podría obedecer, quizás, a que en caso de operaciones comerciales donde interviniera un matrimonio afroporteño, aparecería el hombre como único responsable. En cuanto a la compraventa donde tanto compradores como vendedores fueran integrantes de la raza africana, sólo hemos hallado 42 casos (en tres de ellos participan esclavos, ya sea como comprador, ya como vendedor). El cuadro 4 revela, en cambio, que las operaciones inmobiliarias entre afroporteños y blancos eran más frecuentes, y que entre las personas de raza blanca intervinientes, la mayoría recibía tratamiento de "Don". Llama la atención que una sociedad tan prejuiciosa, los blancos celebraran contratos de compraventa con negros y mulatos, algunos de los cuales eran esclavos, adquirieran y, en algunos casos, fueran a vivir a casas que habían sido habitadas por integrantes de la "raza infame", o entregaran la que había sido su morada a alguno de estos últimos; llama la atención, por fin, el lugar alcanzado por los afroporteños en la sociedad colonial, dentro de la cual estaba en igualdad de condiciones respecto del hombre blanco, al menos en cuanto al aspecto comercial se refiere. 


\section{Afroporteños propietarios de esclavos}

Los documentos consultados nos permitieron encontrar un total de 63 operaciones de compraventa de esclavos realizadas entre afroporteños y blancos. El total de esclavos involucrados fue de 65 (33 vendidos, 32 comprados), sólo 8 de los mismos eran mulatos, ignorándose para otros su proporción sanguínea, y 35 son de sexo masculino.

Sólo 7 de las personas de raza blanca que participaron en dichas compraventas no recibían tratamiento de "Don", mientras que solamente se encontró una operación (trueque de esclavos) entre dos integrantes de la raza africana. ${ }^{40}$ También hemos hallado 13 manumisiones (sólo 2 de ellas son gratuitas) y varios testamentos en donde el (o la) otorgante resultan ser afroporteños dueños de esclavos.

Precisamente, el testamento de María Isabel, negra libre, natural de Guinea, casada con Manuel López, esclavo de Don Isidoro López Farías, es muy interesante ya que declara poseer sitio y casa, y además, una negrita llamada Ana. ${ }^{41}$ Una vez más, nos encontramos frente a un caso donde uno delos integrantes del grupo familiar es propietario de bienes raíces $-\mathrm{y}$ aquí también de un esclavo-, mientras alguno de sus miembros permanece en esclavitud.

En cuanto al valor de los esclavos, hemos notado precios deprimidos durante los primeros treinta años del lapso en estudio; durante la segunda parte del período, sin embargo, subieron considerablemente, aunque observamos altibajos. De todas formas, el precio promedio para las seis décadas de un esclavo adulto estuvo alrededor de los 250 pesos, si bien el valor podía aumentar de modo significativo si el siervo poseía un oficio. ${ }^{42}$

Petit Muñoz afirma, refiriéndose a los dueños de esclavos, que éstos podían ser "todas las personas de la especie humana, naturales o jurídicas, con la sola excepción de los esclavos mismos". ${ }^{43}$ Es por eso que ha despertado nuestro interés el hallazgo de dos documentos, los cuales transcribiremos parcialmente; se trata de una venta y de un proceso judicial. Este último se sigue contra el negro Bentura Benítez:

“...A los Alcaldes ordinarios de la ciudad de Montevideo hago saber — asienta Don Gregorio Ramos Mejía, alcalde ordinario de primer voto del Cabildo de Buenos

40 AGN, PN, r. 3, 1757-1758, f. 545v., 9 de agosto de 1758.

41 AGN, PN, r. 3, 1798, f. 89, 8 de marzo de 1798.

42 Ver nuestro trabajo "Precios internos de esclavos ..."

43 Petit Muñoz et alter: La condición jurídica ..., pág. 307. 


\section{NEGROS Y PARDOS PROPIETARIOS DE BIENES RAÍCES Y DE ESCLAVOS}

Aires - cómo en este mi juzgado se está procesando criminalmente contra un negro llamado Bentura Benítez, o Chavarría, por la muerte que se le acusa haber perpetrado en esta ciudad en la persona de otro negro nombrado Francisco Cribau, esclavo de otra negra, Francisca de Paula, sierva de Vicente Albarez (alias) Ropanda o Ropandilla, soldado que fue del Regimiento fijo de Infantería...." ${ }_{44}$

El otro documento es una venta de esclavo; se transcribirá el encabezamiento del mismo:

"Sea notorio como yo, Don Vicente Rebuelta Belarde, vecino de esta ciudad, por la presente otorgo que vendo y doy en venta real...a Francisco, negro esclavo del señor Brigadier Don Jaime Sanjust, a quien para efecto de otorgarle esta venta me he informado del dicho su amo acerca de la realidad o manejo de su esclavo, de que tenía licencia del expresado su amo para comprar el mío, quien me respondió a continuación de una carta que le escribí acerca del caso presente, y me respondió que, instruido de mi contenido, concedía licencia al dicho su esclavo para la compra de mi negro Luis, y que pudiese ejecutarla con la mayor satisfacción...”.

El negro Francisco, esclavo de oficio cocinero, compró en 400 pesos. al negro Luis. ${ }^{45}$

Estos dos casos son realmente interesantes dado que no abundan, y por esa misma razón no es conveniente sacar conclusiones apresuradas. Sin embargo, existen, son reales y nos dicen que hubo esclavos que fueron amos de otros esclavos, ${ }^{46}$ lo cual quizá no llame la atención desde un punto de vista estrictamente económico, pero sí del social e, incluso, del legal.

Por último, sobre el tema del "negro" como amo del "negro", es interesante destacar lo señalado por Carlos Aguirre en su estudio sobre la esclavitud en Lima hacia mediados del siglo XIX:

“... la propiedad de esclavos estaba tan profundamente arraigada aun entre la población de escasos recursos, y era visto como algo tan normal que personas de origen negro y, probablemente, ellas mismas ex-esclavas, se esmeraban también en convertirse en propietarias de esclavos...; para muchos esclavos el horizonte al que aspiraban no era en modo alguno liquidar la esclavitud como sistema, sino salir de ella para acceder a una mejor posición social, imitando los usos y valores de los propietarios esclavistas". ${ }^{47}$

44 AGN, Tribunales, legajo 149, expediente 13, IX-37-6-6, 1790 (el subrayado es nuestro).

45 AGN, PN, r. 6, 1786, f. 240, 9 de junio de 1786 (los subrayados son nuestros).

46 Resulta interesante comparar este hecho con aquél que se dio en Perú y que fuera estudiado por Harth-Terré: el indio como amo del africano y su participación en la compraventa de esclavos, teniendo en cuenta que no sólo se refiere a la nobleza indígena sino también al indio del común. Cfr. Harth-Terré, Emilio: Negros e indios, un estamento social ignorado del Perú colonial, Lima, 1973. Con respecto al continente negro, Ki-Zerbo señala que en el reino Kongo hubo esclavos que poseían esclavos. Cfr. Ki-Zerbo, Joseph: Historia del Africa Negra, t. 1, Madrid, 1980, pág. 304.

47 Aguirre: Agentes de su propia libertad ..., págs. 66-67. 


\section{Observaciones finales}

En un alegato contra los prejuicios raciales (un documento de fines del período hispánico) se señala que

"es constante que las innumerables personas que hay en la América de las referidas castas envilecidas por sola su condición y nacimiento no son admitidas en las escuelas públicas de primeras letras a fin de que no se junten y rocen con los hijos de los Españoles. Por la misma razón no son admitidas en la carrera de las armas, ni alguna otra Junta, Congregación o Comunidad de Españoles. Si delinquen son fatigados con los vergonzosos y afrentosos castigos que las Leyes previenen para las personas viles e infames...". ${ }^{48}$

Obviamente, no pretendemos negar la existencia del racismo y la marginación en la sociedad colonial, pero sí creemos que pueden hallarse matices en las relaciones comerciales entabladas entre blancos y afroporteños. Con relación a este tema, algunos de estos últimos se distinguieron por sobre sus hermanos de raza por la frecuencia y/o volumen de su participación en distintas operaciones mercantiles.

Pablo Agüero, negro libre, aparece por lo menos doce veces haciendo negocios entre los años 1786 y 1789: vende siete esclavos, compra tres, vende un sitio, hace un trueque de sitio y casa, y pide un permiso para edificar en donde acompaña un plano de las construcciones que piensa realizar. ${ }^{49}$ En 1792 y 1793 encontramos un Pablo Agüero que no sabemos si es la misma persona que la anterior; a diferencia del primero, este último firma los contratos de compraventa.

Manuel Arroyo, también negro libre, con su residencia en el barrio de Concepción, interviene en dieciséis operaciones comerciales entre los años 1768 y 1805: vende tres esclavos, compra cuatro, vende un sitio y una casa, compra siete terrenos y sabemos que era oficial de media cuchara desde $1776 .{ }^{50}$

48 "Contra los prejuicios raciales. Alegato a favor de los negros, zambos, mulatos, mestizos, cuarterones, etc. ...", Revista de la Biblioteca Nacional, t. 4, n. ${ }^{\circ}$ 13, Buenos Aires, primer trimestre de 1940, pág. 122.

49 "Plano y alzado de las obras que proyectaba construir Pablo Agüero, negro libre, en el barrio de Montserrat", AGN, Permisos para edificar (1786 y enero-mayo de 1787), IX-11-1-1, 13 de marzo de 1787; en el mismo legajo también encontramos el plano de Antonio Romero, pardo libre, propietario en el barrio de Concepción; el de Mariana Patrón (o Padrón), mujer "libre de toda esclavitud", del barrio de las Catalinas se encuentra en AGN, Permisos ... (junio-diciembre de 1787 y 1788 1792), IX-11-1-2.

50 AGN, Tribunales, legajo 66, expediente 37, IX-36-2-6, (lista de albañiles con relación al censo de artesanos ordenado por el virrey Vértiz), f. 4, 21 de agosto de 1780. 
Los documentos también nos dicen que participó en compraventas "extrajudiciales". ${ }^{51}$

La familia Falcón estaba formada por Ignacio Falcón, natural de Congo, y su esposa, Catalina de Aguila (o Angulemas), de nación Mina, ambos de condición libre y, aparentemente, sin hijos. Sus bienes constan de un terreno, una casa ubicada en la calle de Las Torres, y hacia 1778 (testamento de la negra) nueve esclavos. No sabemos el oficio de Ignacio, pero sí, en cambio, que al menos parte de las entradas del matrimonio provenían del alquiler que cobraban por algunos cuartos de la casa. De dicha familia tenemos noticias entre los años 1753 y 1794: compra de un esclavo, compra de un sitio, cuatro manumisiones (dos ellas múltiples), tres testamentos, dos codicilos, el testamento del albacea de Ignacio Falcón y también el testamento de una negra que nombra a este último como segundo albacea.

Por uno de los codicilos del negro ${ }^{52}$ nos enteramos de que hubo un proceso judicial donde se ventiló una libertad prometida y luego negada, entre su mujer y una de las esclavas. Finalmente sabemos que todos los esclavos quedaron libres. Aun luego de fallecidos ambos cónyuges tenemos noticias de la familia Falcón por el testamento del albacea de Ignacio, Don Joaquín de Viera y Gago

“... Declaro que soy albacea, nombrado por la real justicia, del finado Ignacio Falcón, negro libre, cuya testamentaría no tengo evacuada, a causa de estar en litigio sobre solicitar un negro que fue esclavo del dicho difunto heredarle, pretendiendo se le tenga por hijo de aquél, de lo que tengo instruido a mis albaceas ...". ${ }^{33}$

En síntesis, queremos destacar el lugar alcanzado por algunos integrantes de la raza africana en la sociedad rioplatense. Observamos que una cantidad nada despreciable de éstos tenía acceso a una vivienda propia o, en su defecto, a un terreno en donde con sus propias manos levantarían la que sería su casa, en principio quizá modesta, pero que con el correr de los años iba a ser beneficiada con ampliaciones y mejoras. Hemos visto también que los precios de dichos inmuebles en algunos casos alcanzaban cifras considerables, más aún si pensamos que en el pago o cobro de las mismas estaban involucradas personas que habían permanecido en esclavitud buena parte de

51 El término "extrajudicialmente" aparece reiteradamente en los documentos de la época. Se refiere sin duda a aquellos contratos donde no intervenía el notario; en estos casos no existía escrituración (lo cual abarataba la compraventa), y se extendía el llamado "papel simple", en el cual las partes especificaban la operación realizada.

52 AGN, PN, r. 6, 1793, f. 25v., 21 de enero de 1793.

53 AGN, PN, r. 3, 1794-1795, f. 79v., 23 de junio de 1794. 
sus vidas o que, incluso, continuaban esclavizadas al momento de efectuarse la operación. No es de extrañar, sin embargo, que la gran mayoría de los afroporteños, en consonancia con sus modestas entradas, habitaran barrios alejados del centro de la ciudad, tal cual se desprende de los datos arriba analizados. Sabemos que los contratos de compraventa eran celebrados más frecuentemente con un blanco que con otro afroporteño, y que por lo general el blanco ocupaba un lugar destacado dentro de la sociedad colonial. En otros casos, como en el de Ignacio Falcón y su esposa, son poseedores de un buen número de esclavos. Resumiendo, en el Buenos Aires tardocolonial, si bien existente, la marginación cromática parecería haberse atenuado en la relación comercial entre blancos y negros.

Por último, unas pocas palabras respecto de la esclavitud del "hombre de color" por parte del "hombre de color". No tenemos datos para afirmar que un amo negro era mejor - desde el punto de vista del esclavo- que uno blanco; es posible que así fuera. Sin embargo, sabemos que algunos integrantes de la raza africana lucharon ante la justicia (caso de Ignacio Falcón y su esposa) por conservar sus esclavos; éstos, en última instancia, eran un bien económico. Otro ejemplo ilustrativo es el de Rosalía Estela, parda libre, que desde 1793 a 1800 mantuvo como esclava a su sobrina Polonia, también mulata; previo pago de 225 pesos, cantidad facilitada por la madre, de condición libre, de la pardita (tiene 15 años), recibe su carta de libertad. ${ }^{54}$ En otros casos, el comercio negrero era realizado por integrantes de la raza africana, como por ejemplo Manuel Joaquín, mulato portugués, que condujo una partida de esclavos a Buenos Aires. ${ }^{55}$

Desde un punto de vista socio-cultural parecen lícitas e, incluso, aconsejables, las prácticas esclavistas llevadas a cabo por los afroporteños, ya que las pautas culturales de esa sociedad no sólo las permitían, sino que las alentaban. De esa manera, el "negro", como amo de otros "negros", estaba "más cerca" del blanco, asimilaba su cultura y se integraba socialmente.

En todo caso, desearíamos que la presentación que hemos realizado de algunos matices en las relaciones sociales coloniales rioplatenses, con respecto a otras realidades históricas, no sea considerada como una pretensión de "rehabilitar" la esclavitud. ${ }^{56}$ Nada más alejado de nuestro pensamiento.

54 AGN, PN, r. 5, 1800-1801, f. 116, 27 de mayo de 1800.

55 AGN, PN, r. 4, 1808, f. 306v., 2 de julio de 1808.

56 Ver la opinión de Carlos Aguirre con relación a la posición del historiador brasileño Jacob Gorender en contra de los que han documentado los logros de los esclavos dentro del sistema pues sólo buscarían "rehabilitar" la esclavitud. Aguirre: Agentes de su propia libertad ..., pág. 229. 